\title{
Promoção da Saúde Mental - Tecnologias do Cuidado: vínculo, acolhimento, co-responsabilização e autonomia
}

\author{
Promotion of Mental Health - Technologies for Care: \\ emotional involvement, rteception, co-responsibility \\ and autonomy
}

\author{
Maria Salete Bessa Jorge ${ }^{1}$ \\ Diego Muniz Pinto ${ }^{2}$ \\ Paulo Henrique Dias Quinderé ${ }^{2}$ \\ Antonio Germane Alves Pinto ${ }^{3}$ \\ Fernando Sérgio Pereira de Sousa ${ }^{2}$ \\ Cinthia Mendonça Cavalcante ${ }^{2}$
}

${ }^{1}$ Programa de PósGraduação em Saúde Coletiva, Centro de Ciências da Saúde, Universidade Estadual do Ceará. Av. Paranjana, 1700, Itaperi. 60740-000 Fortaleza CE. masabejo@bol.com.br ${ }^{2}$ Departamento de Enfermagem, Universidade Estadual do Ceará.

${ }^{3}$ Universidade Regional do Cariri.

\begin{abstract}
Healthcare relations serve as efficient devices for the promotion of mental health and the development of comprehensive practices. This study seeks to analyze the measures that make mental healthcare possible in the daily operations of a Psychosocial Healthcare Center (CAPS). It is qualitative research adopting a critical and reflexive approach conducted in CAPS in the municipality of Sobral in the State of Ceará. Complying with regulations, the study was submitted for analysis by the Committee for Ethics in Research adhering to norms for research involving human beings. For data gathering, conducted between May and July 2008, semi-structured and systematic observation interview techniques were used. The research subjects involved 20 people, distributed into three groups: group I (mental health workers-8); group II (users-7) and group III (relatives of users-5). The material was organized and analyzed using principles of critical hermeneutics. According to the results, in the daily operations of CAPS, the relations of care and its devices (reception, emotional involvement, coresponsibility and autonomy) make the transversal adaptation of psychosocial practices possible. The dialogues were derived from meetings of mental health workers, users and relatives in their quest for healthcare solutions.
\end{abstract}

Key words Mental health, Promotion of health, Care
Resumo As relações de cuidado funcionam como dispositivos eficazes para a promoção da saúde mental e para o desenvolvimento de práticas integrais. Objetiva-se analisar os dispositivos que possibilitam o cuidado em saúde mental no cotidiano do Centro de Atenção Psicossocial (CAPS). Trata-se de uma pesquisa qualitativa de abordagem crítica e reflexiva realizada no CAPS do $\mathrm{Mu}$ nicípio de Sobral-CE. O estudo foi submetido à análise do Comitê de Ética em Pesquisa adequando-se às normas da pesquisa envolvendo seres humanos. Para a coleta de dados, realizada no periodo de maio a julho de 2008, foram utilizadas as técnicas da entrevista semi-estruturada e observação sistemática. Os sujeitos da pesquisa foram 20 pessoas, distribuídas em três grupos: grupo I (trabalhadores de saúde mental-8); grupo II (usuários-7) e grupo III (familiares dos usuários-5). Após coletado, o material foi organizado e analisado pelos pressupostos da hermenêutica crítica. Conforme os resultados evidenciam, no cotidiano do CAPS, as relações de cuidado e seus dispositivos (acolhimento, vínculo, co-responsabilização e autonomia) possibilitam a transversalização da prática psicossocial, (re) construindo espaços de diálogo no encontro dos trabalhadores de saúde mental, usuários e familiares na busca da resolubilidade da atenção à saúde.

Palavras-chave Saúde mental, Promoção da saúde, Cuidado 


\section{Introdução}

Por décadas, o atendimento ao doente mental no Brasil esteve ligado ao modelo centrado no hospital, cujo tratamento oferecido limitava-se a internações prolongadas, mantendo o doente afastado do seu âmbito familiar e social. Nos anos 1970, a modificação do modelo asilar foi discutida e implementada por meio de lutas e conquistas da reforma psiquiátrica, a qual dia-a-dia vem se consolidando nas políticas de saúde mental. Historicamente, a desinstitucionalização permeia o campo da saúde mental entre os trabalhadores, os familiares e a comunidade em geral ${ }^{1}$.

Com o advento do paradigma psiquiátrico e a evidenciação da subjetividade no processo terapêutico, foi possível delinear a superação dos hospícios para compor uma assistência integral e resolutiva. Tenta-se evitar, desse modo, o abandono das pessoas nas ruas ou por seus familiares com vistas a propiciar um efetivo acompanhamento do sujeito em sua existência e em relação às suas condições de vida ${ }^{2}$.

Durante muito tempo, a saúde mental constituiu um campo de exclusão. Entretanto discussões sobre a cronificação dos pacientes, o sistema asilar, o modelo biomédico, a não reinserção social, a violação dos direitos humanos e de cidadania fizeram surgir iniciativas políticas, científicas, sociais, administrativas e jurídicas. Tais iniciativas trouxeram à tona novas estratégias voltadas à reabilitação e à recuperação desses indivíduos com transtorno mental, propondo a valorização do cuidar e uma nova forma de pensar no processo saúde-doença².

As estratégias formuladas intentam uma ressignificação das práticas e dos serviços de saúde, ainda norteados por um modelo positivista de atenção à saúde. Neste, os sujeitos que participam dos encontros efetivados nos espaços da saúde tendem a se reduzir à unidimensionalidade conformada por uma leitura tecnocientífica, construtora de objetos, na qual um é o próprio substrato dos recortes objetivos (o paciente) e o outro aquele que produz e maneja esses recortes (o profissional) . $^{3}$.

Como propõe a literatura, o trabalho em saúde deve ser permeado pelos encontros diversos e pelas múltiplas visões na relação entre o trabalhador e o usuário. Mas, lembrando, a relação terapêutica também é constituída pela dor, sofrimento, vivências e percepções de vida em que os saberes e práticas no campo da saúde mental precisam estabelecer mecanismos para tornar evidente os elementos assistenciais, subjetivos e sociais ${ }^{4}$.
Ainda como mostra a literatura, a organização das práticas de saúde e das relações terapêuticas na produção do cuidado com ênfase nas tecnologias leves possibilita a forma efetiva e criativa de manifestação da subjetividade do outro, a partir dos dispositivos de acolhimento, vínculo, autonomia e responsabilização contidos nessa organização da assistência à saúde 5 .

Desse modo, exige-se a valorização das tecnologias leves ou relacionais pelos sujeitos componentes da prática nos serviços de saúde mental, aliada à perspectiva emancipatória de operar o cuidado conforme os pressupostos da reforma psiquiátrica e da atenção psicossocial.

Por suas especificidades, o trabalho em saúde não pode ser globalmente capturado pela lógica do trabalho morto, expresso nos equipamentos e nos saberes tecnológicos estruturados, pois seu objeto não é plenamente estruturado e suas tecnologias de ação mais estratégicas se configuram em processos de intervenção em ato. Ele opera em tecnologias de relações, de encontros de subjetividade, para além dos saberes tecnológicos estruturados ${ }^{6}$.

De acordo com o estabelecido, as tecnologias em saúde são divididas em leves, leve-duras e duras. As leves compreendem as relações interpessoais, como a produção de vínculos, autonomização e acolhimento; as leve-duras dizem respeito aos saberes bem estruturados, como a clínica médica, a epidemiologia e a clínica psicanalítica; e as duras são compostas por equipamentos tecnológicos do tipo máquina, normas e estruturas organizacionais ${ }^{7}$.

$\mathrm{Na}$ prática cotidiana dos serviços de saúde deve-se priorizar a tecnologia leve como instrumento para atingir a integralidade e a humanização do cuidado. Essa prática pode ser fundamentada no acolhimento, no diálogo, no vínculo, na co-responsabilidade e na escuta ativa entre profissional e usuário dos serviços de saúde. Isto porque a integralidade está presente no encontro, na conversa, na atitude do profissional que busca prudentemente reconhecer, para além das demandas explícitas, as necessidades dos cidadãos no concernente à sua saúde. A integralidade está presente também na preocupação desse profissional com o uso das técnicas de prevenção, tentando não expandir o consumo de bens e serviços de saúde, nem dirigir a regulação dos corpos ${ }^{8}$.

$\mathrm{Na}$ busca dessa totalidade do cuidado aprofundam-se as relações subjetivas entre trabalhador/usuário/serviço de saúde. Com base nessa perspectiva, os onipresentes e substantivos diálogos que entretecem todo o trabalho em saúde não 
conformam apenas a matéria por meio da qual operam as tecnologias, mas também a conversação; ela própria, na forma como se realiza, constitui um campo de conformação de tecnologias ${ }^{5}$.

Esses dispositivos relacionais (acolhimento/ vínculo/co-responsabilização/autonomia) representam possibilidades de se construir uma nova prática em saúde. Passa-se, então, a compreendê-la como ações comunicacionais, atos de receber e ouvir a população que procura os serviços de saúde, dando respostas adequadas a cada demanda em todo o percurso da busca, desde a recepção e o atendimento individual ou coletivo, até o encaminhamento externo, retorno, remarcação e alta ${ }^{9}$.

Uma das possibilidades para edificar novas formas de se fazer saúde seria a potencialização do dispositivo acolhimento, articulado ao estabelecimento de vínculo entre usuários, trabalhadores de saúde e gestores do sistema de saúde, em busca da humanização do atendimento ${ }^{10}$. Portanto, o acolhimento permeia toda terapêutica e, desse modo, propicia um cuidado integral ao usuário de saúde.

Etimologicamente, vínculo é um vocábulo de origem latina, e significa algo que ata ou liga pessoas, indica interdependência, relações com linhas de duplo sentido, compromissos dos profissionais com os pacientes e vice-versa. A constituição do vínculo depende de movimentos tanto dos usuários quanto da equipe ${ }^{10}$.

$\mathrm{O}$ vínculo pode ser uma ferramenta que agencia as trocas de saberes entre o técnico e o popular, o científico e o empírico, o objetivo e o subjetivo, convergindo-os para a realização de atos terapêuticos conformados a partir das sutilezas de cada coletivo e de cada indivíduo. Ele favorece outros sentidos para a integralidade da atenção à saúde ${ }^{11}$.

Acolhimento e vínculo são decisivos na relação de cuidado entre o trabalhador de saúde mental e o usuário. Nesta relação, o acolhimento e o vínculo facilitam a construção da autonomia mediante responsabilização compartilhada e pactuada entre os sujeitos envolvidos nesta terapêutica.

A construção da autonomia ocorre na medida em que ambos conseguem lidar com suas próprias redes de dependências, co-produção de si mesmo e do contexto. Nesse caso, a formação da atitude co-responsabilizada requisita o compromisso e o contrato mútuo, evitando dissonâncias cotidianas na possibilidade de se conviver e de se trabalhar em prol de algum propósito ${ }^{12}$.

Ante a importância da utilização das tecnologias leves em saúde na procura da integralidade do cuidado, deve-se ter sempre em vista o sentido final do trabalho em saúde, qual seja, defender a vida dos usuários, individuais e ou coletivos, por meio da produção do cuidado. Assim, a meta é reduzir o sofrimento, melhorar a qualidade de vida e desenvolver a autonomia nas pessoas para viverem a vida ${ }^{13}$. Nesse prisma, o artigo em elaboração tem por objetivo analisar os dispositivos que possibilitam o cuidado em saúde mental no cotidiano do Centro de Atenção Psicossocial (CAPS).

\section{Metodologia}

Pesquisa qualitativa, dentro de uma perspectiva crítica e reflexiva. Tal metodologia é adequada para a análise do fenômeno social investigado e sua interface com o campo da saúde mental. Nesta abordagem teórico-metodológica, podese dimensionar a compreensão dos significados, dos sentidos, das intencionalidades e das questões subjetivas inerentes aos atos, às atitudes, às relações e às estruturas sociais ${ }^{14}$.

Como local da pesquisa decidiu-se pelo Centro de Atenção Psicossocial do Município de Sobral, Estado do Ceará, Brasil, um dos serviços substitutivos da Rede de Atenção Integral à Saúde Mental da cidade escolhida como campo empírico.

Para a coleta de dados foram utilizadas as técnicas de entrevista semi-estruturada e observação sistemática. Os sujeitos da pesquisa foram 20 pessoas, conforme coleta no período de maio a julho de 2008, distribuídas em três grupos: grupo I - trabalhadores de saúde mental (2 Terapeutas ocupacionais; 1 Enfermeiro; 1 Assistente social; 2 Psicólogos; 1 Recepcionista; 1 Porteiro); grupo II - usuários (7) e grupo III - familiares dos usuários (5).

Quanto à escolaridade dos participantes da pesquisa, eram trabalhadores de saúde de nível superior e médio. Segundo a definição de trabalhadores de saúde conceitua, estes são "todos aqueles que se inserem direta ou indiretamente na prestação de serviços de saúde no interior dos estabelecimentos de saúde ou em atividades de saúde, podendo deter ou não formação específica para desempenho de funções atinentes ao setor"15.

Como critério de inclusão, os usuários e os familiares que participaram do estudo deveriam estar há pelo menos seis meses no CAPS e aceitar participar da pesquisa após apresentação e assinatura do termo de consentimento livre e esclarecido.

Adotou-se, então, a amostragem intencional definida pela saturação teórica, a qual, ao esta- 
belecer o tamanho final da amostra em estudo, interrompeu a captação de novos participantes, fundamentada na redundância e convergência de sentido e significado obtido durante a coleta e análise dos $\operatorname{dados}^{16}$.

Conforme definido, as 20 entrevistas e as observações foram orientadas por roteiros preestabelecidos sobre os seguintes pontos: 1) fluxo de atendimento do usuário no serviço de saúde; 2) relação comunicacional e afetiva entre trabalhador/usuário/família (fala - escuta - confiança - respeito - co-responsabilização); 3) construção do projeto terapêutico; 4) vínculo e acolhimento como instrumentos de organização das práticas de saúde.

Como mencionado, a pesquisa é um recorte do Projeto Organização das Práticas de Saúde Mental no Ceará na Produção do Cuidado Integral: dilemas e desafios, aprovado pelo Comitê de Ética em Pesquisa da Universidade Estadual do Ceará.

Para o melhor entendimento do objeto de estudo, a análise do material empírico baseou-se na hermenêutica crítica, na qual o fundamento de análise é a práxis social na perspectiva críticoanalítica. Os passos operacionais foram: ordenação dos dados; classificação dos dados; e, por fim, a análise final dos dados ${ }^{14}$.

Os resultados se conformam na configuração analítica da compreensão do objeto de estudo, dispostos em discursos e observações, constituindo o entendimento temático da categoria Relações de cuidado como ferramentas da prática em saúde mental: acolhimento, vínculo, coresponsabilização e autonomia.

\section{Resultados e discussão}

Relações de cuidado como ferramentas da prática em saúde mental: acolhimento, vínculo, coresponsabilização e autonomia.

Mediante suas novas estratégias, a saúde mental visa atingir um cuidado integral. Para tal, utiliza as relações de cuidado como ferramentas de sua prática. Neste estudo, o espaço contextual é o CAPS Geral. Trata-se de um serviço destinado à população com transtornos mentais do município, que se articula com todos os níveis de complexidade assistencial (atenção básica, hospitalar e de especialidades) e ainda com os outros setores sociais.

Neste espaço, os sujeitos interpenetram suas atividades pela composição multidisciplinar, pois conta-se com quatro médicos psiquiatras, três psicólogos, dois enfermeiros, dois assistentes sociais, dois terapeutas ocupacionais, dois auxiliares de enfermagem, uma psicopedagoga e um administrador, além da equipe de apoio, formada por cinco auxiliares de escritório, três auxiliares de serviços gerais, três zeladores de patrimônio público e um motorista. Num total de trinta trabalhadores.

Mensalmente o serviço atende uma média de 470 pessoas, entre procedimentos intensivo, semi-intensivo e não-intensivo. Mencionados procedimentos são determinados pelo tempo de permanência diário no CAPS, desde momentos semanais, intercalados ou não, até aqueles com permanência de continuidade diária. A demanda dos transtornos evidencia os casos moderados e graves de psicose, transtornos do humor e a esquizofrenia.

Como previsto, a dinâmica de funcionamento prioriza o trabalho em rede, ou seja, concebe a atenção integral em saúde mental, por meio de uma gestão participativa. Esta é efetivada em reuniões para discussão do processo de trabalho, comunicação ampla dos trabalhadores entre si e também a inserção do usuário com suas singularidades na construção do projeto terapêutico.

A organização do serviço está transversalizada pelo acesso referenciado e o acolhimento. Consoante visto em todo o processo assistencial, os dispositivos potencializadores da prática integral em saúde configuram-se no cotidiano diverso e múltiplo do serviço CAPS e na lógica de funcionamento, no fluxo e no cuidado prestado aos usuários.

Consideram-se como tecnologias leves em saúde aquelas implicadas no ato de estabelecimento das interações intersubjetivas na efetuação dos cuidados em saúde. Por espaço das tecnologias leves compreende-se aquele no qual nós, profissionais de saúde, estamos mais imediatamente colocados perante o outro da relação terapêutica ${ }^{5}$.

Conforme exposto, os discursos convergem na seguinte perspectiva: o acolhimento é estabelecido por meio de um atendimento de qualidade, de um tratamento pautado no respeito, no diálogo, na escuta qualificada, no estabelecimento de um elo de confiança e de amizade entre ambos (trabalhadores de saúde e usuários/família).

Muitas vezes, a gente nem conversava sobre mim paciente, a gente conversava sobre trabalho, sobre televisão, sobre o meu curso, sobre a minha faculdade. (Grupo II)

É bom! Eu não tenho o que dizer. Eles me atendem bem aqui, desde o auxiliar de serviço até o médico. (Grupo III)

Então, assim, a questão do respeito é algo fundamental, principalmente a escuta. Hoje em dia, os 
CAPS e todos os serviços que buscam trabalhar na perspectiva da atenção psicossocial, trazem dentro da sua política a questão da valorização do saber, a valorização da experiência, da fala tanto do usuário como do familiar. (Grupo I)

Ao potencializar a relação entre sujeitos, a ênfase no processo relacional incorpora estratégias de aproximação e efetivação de uma prática resolutiva e voltada para o modo de vida de cada usuário. No processo de escuta e acolhimento, o que se desvela é um ato de interpretação mútua entre o que o serviço pode oferecer e o que usuário deseja em sua vida cotidiana. A ação integral ainda é fortalecida pela multiplicidade de visões sobre cada situação no CAPS, já que cada trabalhador absorve e dispõe de saberes e práticas diferenciadas para o trabalho em saúde mental.

Deste modo, é possível reproduzir socialmente a relação assistencial no campo psicossocial, ou seja, redireciona-se a forma de atendimento baseada na intervenção direta na patologia e passa-se a conceber os sujeitos. Visto assim, colocase a doença em parênteses ao deslocar o olhar para o "doente" (sujeito), tornando-o objetivo de todo o trabalho, não apenas a ação técnica. A ênfase é dada pelo processo de "invenção da saúde" e de "reprodução social do paciente". Contudo, "colocar em parênteses" não pode ser pensado como a negação da existência da doença ${ }^{17}$.

Acrescenta-se, ainda, o acolhimento é um dispositivo transversal na conduta terapêutica, pois não é tido apenas como uma parte do processo de cuidado (triagem). Ele perpassa todo o trajeto terapêutico do CAPS.

Inicialmente, a maioria dos CAPS faz triagem e acolhimento no próprio serviço, o CAPS de Sobral, no início, era assim [...] Hoje, o CAPS de Sobral não faz mais triagem, é feita na atenção primária, que é, justamente, um ganho que a gente tá tendo aqui [...] Triar é ver se o paciente que você tá observando, realmente, tem indicação pra ficar no CAPS, naquele serviço, ou se ele é indicação de ficar em outro serviço. Acolhimento é você pegar o paciente que tem indicação daquele serviço e você acolher, fazer a escuta e dali você já construir com ele e a equipe o seu projeto terapêutico. (Grupo I)

É visto que no CAPS de Sobral-CE o acolhimento não é confundido como uma etapa do processo de cuidar (triagem), e sim como um dispositivo que permeia todo o projeto terapêutico do indivíduo desde a sua construção. Sendo um processo compartilhado entre usuário e equipe de saúde mental, perpassa toda a singularidade do indivíduo. (Observação)

O dispositivo acolhimento funciona como uma possibilidade de construir uma nova práti- ca em saúde. Pode ser compreendido como ações comunicacionais, atos de receber e ouvir a população que procura os serviços de saúde, ao dar respostas adequadas a cada demanda em todo o percurso da busca: desde a recepção e o atendimento individual ou coletivo, até o encaminhamento externo, retorno, remarcação e alta ${ }^{9}$.

Especificamente, os dispositivos das tecnologias relacionais transversalizados na prática em saúde mental são o acolhimento, o vínculo, a coresponsabilização e a autonomia. Mas a ênfase ocorre no acolhimento por disponibilizar um processo de escuta, diálogo e valorização do saber do outro. Perpassa toda a terapêutica e o cuidado em saúde, e intensifica o conjunto de dispositivos já mencionados.

Nas relações de cuidado do cotidiano investigado, segundo se nota, o vínculo pauta-se na construção de laços afetivos entre trabalhadores e usuários, na qualidade do atendimento, ou seja, no receber bem aquele usuário, na confiança e na facilidade de comunicação entre esses atores. Além disso, a busca de resolutividade para seus problemas (usuários) com o seu trabalhador de referência é uma forma de percepção do vínculo estabelecido entre eles.

O vínculo no sentido da amizade, no tratamento que você recebe, o jeito que nós se expressamos um com o outro, acho que é o suficiente pra dizer que somos realmente amigos. (Grupo II)

O Doutor que me acompanha, a relação é ótima! A relação é como amigo, né, não é como médico. Ele me dá conselho, me orienta, me ajuda demais! (Grupo II)

Sempre quando querem resolver alguma coisa falam "eu vim falar com você, o que você pode fazer”. Então, eu percebo que há uma reciprocidade, eles me têm muitas vezes como referência, pra tá esclarecendo algo, pra tá agilizando algo com o PSF ou aqui mesmo dentro do serviço, dando algum esclarecimento quanto à conduta medicamentosa, pra mim tá fazendo o contato com o psiquiatra. (Grupo I)

O usuário que frequenta o CAPS tem essa necessidade desse vinculo. Eu percebo muito claro isso, que o vínculo, de certa forma, é uma necessidade terapêutica que se tem, se a gente não conseguir manter esse vínculo que é a aproximação, o respeito, a confiança, o tratamento pode não funcionar [...] A principal coisa que eu vejo necessário pra esse vínculo é a confiança. Esse usuário ter confiança em você como profissional e você responder pra ele nesses momentos que ele precisa do seu apoio [...] O paciente com transtorno mental tem uma carência afetiva muito grande. Desse olhar, dessa atenção que você como profissional oferece e que, muitas vezes, 
ele não tem isso lá fora. Ele é discriminado pela sociedade, pela escola e pela própria família. Então, aqui quando eles chegam, eles buscam isso no profissional, esse vínculo afetivo, ligado ao respeito, ao cuidado, ao olhar, na escuta. Então, eu faço isso e tento fazer esse vínculo tendo em pauta esses quesitos. (Grupo I)

Já formei um laço, porque ele já sabe da história da minha família, do meu filho doente. Se eu mudasse de profissional, eu acharia ruim porque eu teria que contar tudo de novo! (Grupo III)

Conforme é possível observar, os discursos configuram uma direcionalidade de significado dos encontros realizados em cada ato terapêutico. Desse modo, caracterizam determinados construtos relacionais entre os sujeitos na própria relação de cuidado. A necessidade oriunda da vida de cada sujeito e das demandas apresentadas transpõe a dinâmica social, política e gerencial do serviço e refaz-se na conformação prática e operacional pela utilização e evidenciação de tecnologias e ferramentas subjetivas.

Nesse sentido corrobora-se a concepção teórica da ferramenta relacional do vínculo resultante da disposição de acolher uns e da decisão de buscar apoio em outros. Portanto, o vínculo se expressa pela circulação e por afetos entre as pessoas $^{10}$. No trabalho em saúde, a vinculação é uma ferramenta eficaz na horizontalização e democratização das práticas em saúde mental, pois favorece a negociação entre os sujeitos envolvidos nesse processo, isto é, usuários e profissional ou equipe.

A equipe ou profissional de referência são aqueles que têm a responsabilidade técnica pela condução de um caso individual, familiar ou comunitário. Cabe-lhes, de modo integral, ampliar as possibilidades de construção de vínculo entre eles e os usuários ${ }^{18}$.

Mas a construção do vínculo no cuidado em saúde mental depende ainda do modo como os trabalhadores de saúde se responsabilizam pela saúde dos usuários e suas singularidades do processo de cuidar.

Tal constatação na determinação para o estabelecimento do vínculo advém de uma exigência, qual seja, é preciso existir negociações parcializadas na construção mútua de um consenso ao dar resolubilidade de cada necessidade e/ou problema. Contudo, o ato terapêutico não deve estar centrado no trabalhador; tampouco deve ser realizado puramente pela manifestação de desejo do usuário. O vínculo pode, pois, interagir com ambas as possibilidades na busca da conduta cuidadora resolutiva e humanizada ${ }^{12}$.

Inegavelmente, as necessidades de saúde estão contextualizadas no modo de vida de cada sujeito. A condição de vida, o direito à singularidade, o direito às tecnologias de melhoria da vida, o acolhimento e o vínculo na construção da autonomia são características, muitas vezes, mais amplas do que os espaços de intervenção das redes de cuidado em saúde. Cabe, assim, conceber $o$ ato de saúde como intersetorial, porquanto na busca pela resolubilidade, o encontro de vida se dá, às vezes, no mundo vivido.

No trabalho ora elaborado houve divergências quanto ao efeito positivo do vínculo, pois para determinados sujeitos da pesquisa este é prejudicial ao tratamento por causar dependência do usuário em relação ao trabalhador de saúde e vice-versa:

Eu acho que esse vínculo causa muita dependência minha em relação a ela, pode até prejudicar o trabalho e até me prejudicar também, quando uma pessoa fica muito dependente da outra. (Grupo II)

Eu tô bem melhor agora, mas se a minha psicóloga tivesse no passado esse afastamento, eu teria sentido mais, porque eu tava mais vulnerável. Eu tinha mais abertura com ela, foi a pessoa que me atendeu na minha crise, no dia que eu vim pra cá. (Grupo II)

Ela já entende tão bem o meu caso, que se eu fosse pra outra pessoa, que eu teria que explicar tudo de novo, aí, talvez, ele não me entenderia tão bem como ela. Me compreenderia como ela, iria me orientar como ela, aí eu ia ficar confusa e não ia gostar muito não! (Grupo II)

Acho que o vínculo é ruim, porque meu pai não quer ser atendido por outro profissional a não ser a doutora [...] (Grupo III)

Então, se for estabelecer um vínculo muito forte, de confiança e aquilo ali pode ser prejudicial, até mesmo porque é algo forte [...] Então, a gente faz uma escuta acolhedora, mas não é aquele vínculo forte estabelecido no contato inicial. (Grupo I)

Ao se vincular a alguém ou a alguma instituição (uma equipe, um centro de saúde) costumase transferir afetos para essas pessoas ou instituições. Afetos são sentimentos imaginários, apostas que se faz com base na história pessoal de cada um e na imagem produzida pelo serviço ou pelo profissional. Esses afetos podem contribuir ou não para a eficácia da conduta terapêutica $e$ para a manutenção da vida em cada pessoa afetada, seja o trabalhador, ou o próprio usuário ${ }^{10}$.

Por isso, o vínculo pode ganhar variados sentidos (confiança - respeito - amizade - dependência - antipatia), de acordo com os laços de afetividades construídos ao longo da terapêutica entre trabalhador de saúde mental e usuários.

Quanto à co-responsabilização, é uma parceria entre os sujeitos envolvidos no processo de 
cuidar em saúde para a melhoria da qualidade de vida do portador de transtorno mental. Segundo os discursos revelam, essa parceria acontece de forma multilateral, levando em consideração as opiniões e as possibilidades dos trabalhadores/usuários/família na composição do projeto terapêutico. Seguem os discursos:

A gente tem aquela parceria, que eu quero dizer, que eles dão atenção à gente! Eles me atendem bem, me perguntam como é que eu vou. Eles se preocupam! (Grupo II)

Dou opinião no meu tratamento. Assim, você fala o que está sentindo, o que a gente passa e fala pra eles. Aí eles tomam uma atitude. (Grupo II)

A psicóloga não diz exatamente o que eu tenho que fazer, ela deixa que eu me expresse, dê as minhas opiniões, aí ela diz o que eu tô pensando de errado, o que eu tenho que mudar, ela nunca diz que eu tô errada, ela sempre tem a forma dela de dizer que eu tô fazendo não é bem assim. Não é que ela manipule, entendeu? Ela tem a maneira dela de fazer a gente pensar diferente. (Grupo II)

O doutor sempre pergunta se o meu filho tá precisando de alguma coisa [...] Ele leva em conta o que eu falo. (Grupo III)

Realmente, qualquer acompanhamento e o projeto terapêutico nunca podem ser propostos de forma solitária pelo médico. A construção é com o cliente e com o familiar, porque eles têm que estar bem comprometidos. (Grupo I)

Outra coisa que é importante é escutar a opinião familiar. (Grupo I)

Ao se considerar o contexto onde esses sujeitos estão inseridos, a vida vivida de cada um e a própria oferta terapêutica no serviço favorecem a transcendência de valores, práticas e sentimentos acumulados ao longo do tempo. A incorporação dos saberes de cada sujeito no modo de operar a manutenção da vida tem sentido duplo em virtude de ocorrer a transfiguração da relação direta trabalhador de saúde-usuário para também usuário-trabalhador de saúde. Deste modo, a prática coincide com a concepção segundo a qual cuidar não é só projetar, é um projetar responsabilizando-se; um projetar porque se responsabiliza ${ }^{5}$.

Ao mesmo tempo, a responsabilização deve ser mútua, ou seja, uma co-responsabilização entre terapeuta/usuário/serviço/família na tentativa de minimizar os efeitos deletérios da doença mental e estimular a capacidade do usuário para o enfrentamento de seus problemas. Isto, porém, com base nas suas condições sociais, econômicas, culturais e resgatando a sua cidadania, para a própria reinserção na sociedade.

Converge, ainda, o entendimento sobre o desenvolvimento da autonomia dos portadores de transtornos mentais a ocorrer mediante construção do projeto terapêutico que tenta trabalhar as necessidades, as incapacidades, os desejos, os anseios e os sonhos desses usuários. Esse pensamento está sintetizado nos seguintes discursos:

Eu avalio o paciente, aí, através do que ele me mostra na avaliação, é que eu vou construir junto com ele quais são os interesses dele, o que ele gosta, o que ele não gosta, o que ele quer aprender, onde estão as dificuldades dele, é um trabalho feito junto. (Grupo I)

Tentar construir nesse projeto terapêutico algo que também se enquadre como projeto de vida, dar para essas pessoas a capacidade de prover os sonhos, as possibilidades que ela teria. Está "empoderando", por isso a importância de estar discutindo com as pessoas o tratamento, quais são seus sonhos, suas possibilidades e isso seria a questão de reabilitação psicossocial. (Grupo I)

Eu não tenho tempo de fazer atividades aqui no CAPS, só o tratamento com o médico, porque trabalho no interior. Todo dia vou pra Meruoca de manhã e só chego à tarde. (Grupo II)

Eu não faço nenhuma atividade aqui, porque para quem faz tratamento à tarde as atividades são de manhã, e de manhã eu estudo e faço curso Eu estudo pra ser alguém na vida. (Grupo II)

Ele nunca fez nada obrigado, aqui não! (Grupo III)

$\mathrm{Na}$ perspectiva da reabilitação psicossocial pode-se apresentá-la como um conjunto de atividades capazes de oferecer condições amplas de recuperação dos indivíduos por meio da utilização de recursos individuais, familiares e comunitários com vistas a neutralizar os efeitos iatrogênicos e cronificadores da doença e do internamento. Reabilitar significa, pois, ajudar os portadores a sobrepujar suas limitações e incapacidades e promover o autocuidado, no intuito de elevar-lhes a auto-estima, ensejando-lhes a restituição da autonomia, a identidade pessoal e social ${ }^{19}$.

Por fim, ressalta-se a importância de elevar a autonomia dos usuários, ou seja, ampliar a capacidade de compreenderem e atuarem sobre si mesmos e sobre o mundo da vida. O grau de autonomia mede-se pela capacidade de autocuidado, de compreensão sobre o processo saúdedoença, de usar o poder e de estabelecer compromisso e contrato com outros ${ }^{19}$.

Portanto, para atingir o objetivo terapêutico deve-se voltar os trabalhos para as incapacidades, para as necessidades do paciente, tendo em vista o desenvolvimento de condições cada vez melhores e que lhes permita gerenciar sua vida e aumentar suas possibilidades de fazer escolhas ${ }^{20}$. 


\section{Considerações finais}

De modo geral, o estudo propiciou um aprofundamento sobre as relações na produção do cuidado em saúde mental na ênfase analítica dos seus dispositivos na efetivação da integralidade da atenção resolutiva. Evidentemente existem os limites, decorrentes, sobretudo, da própria determinação do cotidiano múltiplo, diverso e dinâmico presente no CAPS.

Considera-se que as ferramentas relacionais envolvidas no processo de trabalho se dinamizam e se articulam na prática cotidiana e determinam-se pelas próprias relações, demandas, necessidades e ofertas envolvidas no cuidado. Tomam sentidos e significados de acordo com a potência afetiva de cada sujeito para com o outro.

$\mathrm{Na}$ operacionalização diária e contínua do trabalho no CAPS segue-se uma compreensão segundo a qual os mecanismos subjetivos de transversalização das ferramentas relacionais direcionam o cuidado em saúde para uma resolutividade emanada das evocações reais da subjetividade. Este cuidado pode ser dimensionado nos atos de escuta e acolhimento, no diálogo próximo de cada singularidade e ainda na confiança constituída de cada sentimento, vínculo e compromisso para com o outro.

Como se depreende, a concepção teórica dos dispositivos cartografados no cotidiano dos serviços de saúde mental possibilita entender o real, o vivido no espaço micropolítico de cada encontro. Transpor o imaginário e efetivar a prática é apropriar-se dos conceitos como ferramentas e assim potencializar sua utilização na construção de ações mais próximas do cotidiano e de cada subjetividade.

$\mathrm{O}$ acolhimento funcionando como um dispositivo capaz de (re)estruturar o cuidado integral em saúde mental, transpondo os conceitos de patologia e de diagnóstico da doença mental, ressaltando a subjetividade e a singularidade de cada indivíduo que é atendido no CAPS. Esse dispositivo de base relacional é compreendido no diálogo entre trabalhador de saúde e usuário/ família, na escuta, no atendimento e na resolubilidade da problemática de saúde desses sujeitos, transversalizando toda a terapêutica.

O vínculo, então, favorece o cuidado integral por democratizar e horizontalizar as práticas em saúde, na medida em que constrói laços afetivos, confiança, respeito e a valorização dos saberes dos usuários/família/trabalhadores de saúde. Desse modo, propicia o desenvolvimento da coresponsabilização, da parceria desses sujeitos para a melhoria da qualidade de vida do portador de transtorno mental.

A autonomia como dispositivo do cuidado integral é o resgate da cidadania dessas pessoas, buscando a auto-estima, o poder contratual e o autocuidado, tendo como pilar o projeto de vida de cada usuário do CAPS. É preciso trabalhar as incapacidades, as necessidades, os medos, as angústias e os sonhos desses indivíduos para que possam, um dia, voltar a gerenciar suas vidas.

Dessa forma, os dispositivos do cuidado integral se transversalizam no cotidiano do CAPS principalmente no ato de acolher e no vínculo construído nas relações terapêuticas. A autonomia e a co-responsabilização ainda requisitam dos sujeitos envolvidos uma maior capacidade de articulação com as próprias demandas imaginárias que se conformam no contexto subjetivo de cada trabalhador e usuário.

A partir da análise, conforme se observa, a resolubilidade somente tornar-se-á real na medida em que todos estes dispositivos suprirem as necessidades de saúde da população em cada ato cuidador.

Embora o cotidiano do CAPS seja tenso, é também harmônico; a significação se faz no trajeto terapêutico. Enquanto a estática parece visualizar-se em espaços rígidos, a dinâmica configura-se como um constante processo de transformação e conformação social. Nesse trilhar é possível o surgimento de novos sujeitos e novas práticas que ressignifiquem continuamente o cuidado em saúde mental no SUS. 


\section{Colaboradores}

MSB Jorge, DM Pinto, PHD Quinderé, AGA Pinto, FSP Sousa e CM Cavalcante participaram igualmente de todas as etapas da elaboração do projeto.

\section{Referências}

1. Waidman MAP, Jouclas VMG, Stefanelli MC. Família e reinserção social do doente mental: uma experiência compartilhada pela enfermeira. Revista Ciência, Cuidado e Saúde 2002; 1(1):97-100.

2. Amarante P. Saúde mental e atenção psicossocial. Rio de Janeiro: Fiocruz; 2007.

3. Ayres JRCM. Hermenêutica e humanização das práticas de saúde. Cien Saude Colet 2005; 10(3):549-560.

4. Fonseca AF, Corbo AMA, organizadores. O território e o processo saúde-doença. Rio de Janeiro: EPSJV/Fiocruz; 2007.

5. Ayres JRCM. Cuidado e reconstrução das práticas de saúde. Interface 2004; 8(14):73-92.

6. Merhy EE. Em busca de ferramentas analisadoras das tecnologias em saúde: a informação e o dia a dia de um serviço, interrogando e gerindo trabalho em saúde. In: Merhy EE, Onocko R, organizadores. Agir em saúde: um desafio para o público. São Paulo: Hucitec; 1997. p. 113-160.

7. Mendes-Gonçalves RB. Tecnologia e organização social das práticas de saúde. São Paulo: Hucitec; 1994.

8. Gomes MCPA, Pinheiro R. Acolhimento e vínculo: práticas de integralidade na gestão do cuidado em saúde em grandes centros urbanos. Interface 2000; 9(17):287-301.

9. Santos AM, Assis MMA, Rodrigues AAAO, Nascimento MAA, Jorge MSB. Linhas de tensões no processo de acolhimento das equipes de saúde bucal do Programa Saúde da Família: o caso de Alagoinhas, Bahia, Brasil. Cad Saude Publica 2007; 23(1):75-85.

10. Campos GWS. Reflexões sobre a clínica ampliada em equipes de saúde da família. In: Campos GWS. Saúde Paidéia. São Paulo: Hucitec; 2003. p. 68.

11. Santos AM, Assis MMA, Nascimento MAA, Jorge MSB. Vínculo e autonomia na prática de saúde bucal no Programa Saúde da Família. Rev Saude Publica 2008; 42(3):464-470.

12. Campos GWS. Comentários sobre analogias e diferenças entre os métodos Paidéia e o "interrogativo". Interface 2007; 11(22):345-363.

13. Merhy EE. O ato de governar as tensões constitutivas do agir em saúde como desafio permanente de algumas estratégias gerenciais. Cien Saude Colet 1999; 4(2):305-314.

14. Minayo MCS. O desafio do conhecimento: pesquisa qualitativa em saúde. $11^{\text {a }}$ ed. São Paulo: Hucitec; 2008.

15. Paim JS. Recursos uma saúde no Brasil. Problemas crônicos e desafios agudos. São Paulo: USP, Faculdade de Saúde Pública; 1994.

16. Fontanella BJB, Ricas J, Turato ER. Amostragem por saturação em pesquisas qualitativas em saúde: contribuições teóricas. Cad Saude Publica 2008; 24(1):17-27.

17. Amarante P. O homem e a serpente: outras histórias para a loucura e a psiquiatria. Rio de Janeiro: Fiocruz; 1996.

18. Campos GWS. O anti-Taylor: sobre a invenção de um método para co-governar instituições de saúde produzindo liberdade e compromisso. Cad Saude Publica 1998; 14(4):863-870. 
19. Jorge MSB, Randemark NFR, Queiroz MVO, Ruiz EM. Reabilitação psicossocial: visão da equipe de Saúde Mental. Rev Bras Enferm 2006; 59(6):734-739.

20. Campos GWS, Amaral MA. A clínica ampliada e compartilhada, a gestão democrática e redes de atenção como referenciais teórico-operacionais para a reforma do hospital. Cien Saude Colet 2007; 12(4):849-859.

Artigo apresentado em 24/05/2009

Aprovado em 30/06/2009

Versão final apresentada em 27/07/2009 